Article

\title{
The Textile Industry and Sustainable Development: A Holt-Winters Forecasting Investigation for the Eastern European Area
}

\author{
Dorel Paraschiv, Cristiana Tudor * and Radu Petrariu \\ International Business and Economics Department, Bucharest University of Economic Studies, \\ Bucharest 010374, Romania; E-Mails: dorel.paraschiv@ase.ro (D.P.); radu.petrariu@alumni.ase.ro (R.P.) \\ * Author to whom correspondence should be addressed; E-Mail: cristiana.tudor@net.ase.ro; \\ Tel.: +40-723-254-342.
}

Academic Editor: Marc A. Rosen

Received: 27 November 2014 / Accepted: 24 December 2014 / Published: 26 January 2015

\begin{abstract}
To achieve sustainable development, massive changes towards fostering a clean and pollution-reducing industrial sector are quintessential. The textile industry has been one of the main contributors to water pollution all over the world, causing more than $20 \%$ of the registered levels of water pollution in countries like Turkey, Indonesia and China (among the G20 group of countries) and also in Romania and Bulgaria (in the Eastern European area), with even more than $44 \%$ in Macedonia. Given the controversy created by the textile industry's contribution to pollution at a global level and also the need to diminish pollution in order to promote sustainable development, this paper comparatively investigates the contribution of the textile industry to the water pollution across Central and Eastern European countries, as well as developed countries. In addition, we employ the Holt-Winters model to forecast the trend of the total emissions of organic water pollutants, as well as of the textile industry's contribution to pollution for the top polluters in Eastern Europe, i.e., Poland and Romania. According to our estimates, both countries are headed towards complete elimination of pollution caused by the textile industry and, hence, toward a more sustainable industrial sector, as Greenpeace intended with the release of its 2011 reports.
\end{abstract}

Keywords: pollution; sustainable industry; textile industry; Greenpeace; exponential smoothing; Holt-Winters forecasting; Poland; Romania 


\section{Introduction}

According to the literature, sustainable development is "socially responsible economic development" that protects "the resource base and the environment for the benefit of future generations". However, in order to achieve sustainable development, massive changes in the industrial sector are needed. More specifically, to foster a significantly more sustainable industry, it is imperative to strive to achieve a clean, pollution-reducing industry.

In 2011, Greenpeace made accusations against several global brands in the fashion industry [1,2], such as Nike, Adidas, Puma, Lacoste, GAP and H \& M, who use providers whose activities seriously pollute the environment in China. The report titled "Dirty Laundry", published by Greenpeace, shows that a long list of companies active in the field of fashion has commercial links with suppliers in China. The activity of these suppliers led to the discharge of chemical substances in the Yangtze and Pearl rivers, impacting the immune system function and the functioning of hormones in humans. Indeed, as shown in [3] the textile industry both uses large volumes of water (it takes approximately 200 liters of water to produce $1 \mathrm{~kg}$ of textiles) and also generates significant volumes of wastewater. Dyeing constitutes a particularly important problem in this respect, as dye houses in India and China are notorious for not only exhausting local water supplies, but for dumping untreated wastewater into local streams and rivers.

A second report issued in 2011 by the same organization [4] (i.e., Dirty Laundry 2: Hung Out to Dry) attests that nonylphenol ethoxylates (NPEs) ("NPEs are a group of chemicals used in the manufacturing of textiles, in particular as surfactants and detergents. NPEs can break down to form NPs, a toxic, persistent, bioaccumulative and hormone-disrupting substance. NP is very toxic to aquatic organisms and may cause long-term adverse effects in the aquatic environment.") are present in the clothing and footwear of 15 leading brands. Ultimately, Greenpeace tried with the release of these reports to force these large companies to eliminate all releases of hazardous chemicals from their supply chains and products by the year 2020 .

In 2013 the Chinese authorities have finally acknowledged the existence of so-called "cancer villages" within the country, after several years, from the emergence of information regarding the above average number of cancer occurrences in residents of some particularly polluted regions in the country. The government has also recognized that "toxic and harmful chemicals" generally prohibited in developed countries are allowed in China and "may endanger human health and the environment in the long run." (Mediafax.com).

Among the hazardous substances, nonylphenol (NP), a synthetic organic compound banned in the European textile industry, is being used extensively by the Chinese textile industry and also in the production of detergents. It is worth mentioning that although NP and NPE are currently restricted under the REACH Regulation (the Regulation on Registration, Evaluation, Authorization and restriction of Chemicals - was enforced on 1 June 2007 and was meant to improve the former legislative framework on chemicals of the European Union) for use in textile processing within the EU, this regulation does not apply in cases where there is no release to wastewater at the site. In addition, there are no restrictions concerning the NP/NPE content of finished textiles within the European Union. Furthermore, NP/NPE is not subject to international controls, so imported textiles in particular are believed to be a source of NPE in the environment, a danger to which all world countries are subject (Environment Agency, 2013). 
Given the controversy created by the textile industry's contribution to pollution at a global level, but also given its proven close relationship with the overall macroeconomic growth in a developing country (see [5]), this paper comparatively investigates the contribution of the textile industry to the water pollution across Central and Eastern European countries, developed countries and China and attempts to forecast the trend of the textile industry's contribution to pollution and, hence, the road towards a more sustainable industrial sector over the next decade for the two top polluting Eastern European countries included in the analysis, i.e., Poland and Romania. Previously, Domańska and Wojtylak [6] employed fuzzy time series models to forecast pollution concentrations by using real meteorological data from different areas in Poland. Furthermore, with applications on the Polish data, [7] attempted to forecast daily air pollution by using support vector machine (SVM) and wavelet decomposition. Other studies propose different time series forecasting methods to study pollution indicators. Among these, [8] proposed a parallel genetic algorithm (GA) to forecast hourly concentrations of urban air pollution in Helsinki. Ziomas et al. [9] proposed some analytical models relating pollutant concentrations in the Greater Athens Area with meteorological and other variables, while [10] used a Bayesian kriged Kalman filtering model. Kurt et al. [11] developed an online air pollution forecasting system for the Greater Istanbul Area by using neural networks, and Ibarra-Berastegi et al. [12] also employed neural networks to forecast five air pollution indicators in six locations in the area of Bilbao (Spain). McCollister and Wilson [13] developed two linear stochastic models to forecast the concentrations of various air pollutants in the Los Angeles area, and more recently [14] developed a model for rational sustainable development in Vilnius. Among studies focused on water pollution forecasting, we encounter [15-17]

The remainder of the paper is organized as follows. Section 2 explains and presents the data, comparatively discusses the evolution of some standard water pollution indicators across G20 and Eastern Europe countries over the last decade and also presents the methodology employed in the econometric investigation. Further, Section 3 discusses the empirical results and model diagnosis, while Section 4 concludes the research.

\section{Experimental Section}

\subsection{Data}

This study uses annual data on two different water pollution indicators across various countries (both G20 economies and Eastern European economies); first, we employ the total emissions of organic water pollutants (measured in kilograms per day), and second, we use data on water pollution caused by the textile industry (measured in percentages of total BOD emissions) ("Organic water pollutants are measured by biochemical oxygen demand, which refers to the amount of oxygen that bacteria in water will consume in breaking down waste. This is a standard water treatment test for the presence of organic pollutants". (World Bank definition). The period we cover for each time series is from 31 December 1990 to 31 December 2007. Some countries have fewer observations, depending on data availability. The source of the data is the World Bank database.

As is revealed in Figure 1, the country with the highest amount of emissions of organic water pollutants in the world is China, with an impressive value of $9,428,874 \mathrm{~kg} / \mathrm{day}$. It is followed by USA $(1,850,753 \mathrm{~kg} /$ day $)$ and Russia $(1,381,683 \mathrm{~kg} /$ day $)$ in the group of $\mathrm{G} 20$ countries. At the opposite side, 
i.e., the lowest polluting G20 countries, we find Saudi Arabia (106,621.2 kg/day) and Argentina $(155,535.5 \mathrm{~kg} /$ day). The Eastern European countries report much lower values for BOD emissions, with the highest values encountered in Poland (359,696 kg per day) and Romania (222,102.50 kg/day); see Figure 2.

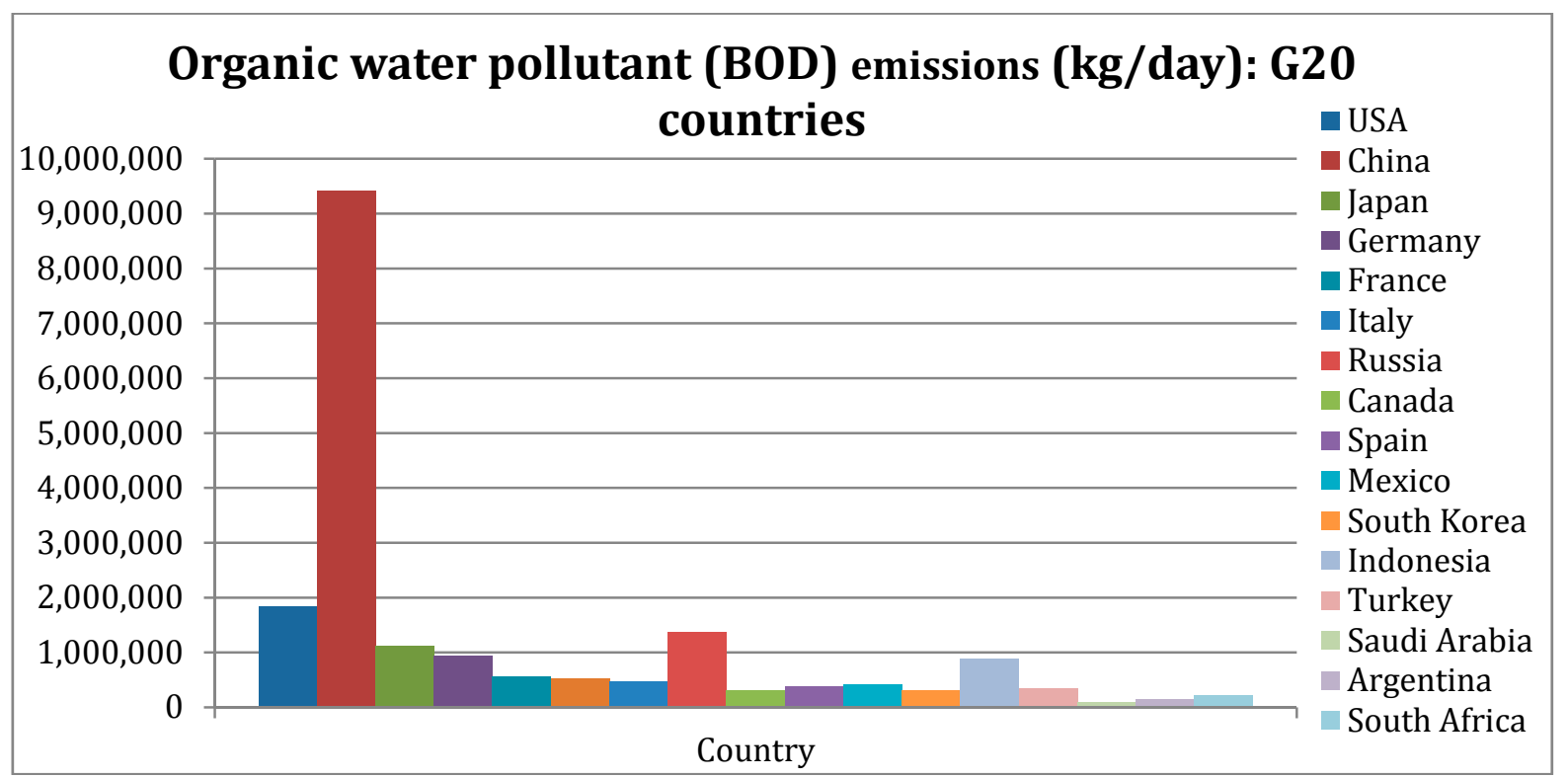

Figure 1. Total emissions of organic water pollutants, G20 countries. BOD, biochemical oxygen demand.

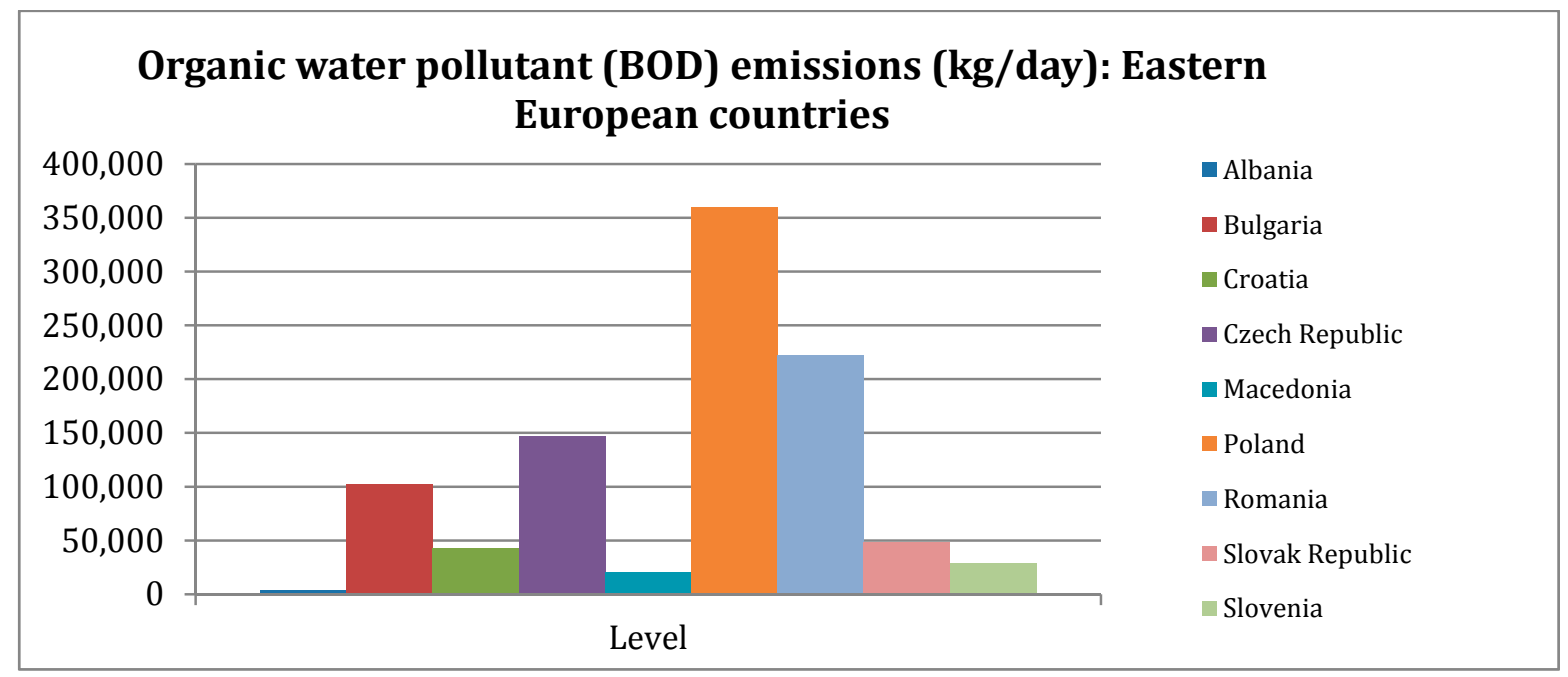

Figure 2. Total emissions of organic water pollutants, Eastern European countries.

Table 1 shows that in Eastern Europe, the percentage of total water pollution that is caused by the textile industry is lowest in the Slovak Republic, Czech Republic and Poland, while in Macedonia, the textile industry is guilty of contributing $44 \%$ to this phenomenon. The good news is that compared to the levels achieved in 1990, most Eastern European countries managed to decrease water pollution caused by the textile industry. The only exceptions are Romania ( $+4.59 \%$ as compared to 1990$)$, Bulgaria $(+17.24 \%)$ and Macedonia $(+28.11 \%)$, which registered increases in this phenomenon (see Table 1). At the opposite side are Slovenia and the Slovak Republic, both countries managing to decrease water pollution caused by the textile industry by more than 43 percent over the last ten reported years. 
Table 1. Water pollution caused by the textile industry, Eastern Europe.

\begin{tabular}{lccccc}
\hline \multicolumn{1}{c}{ Country } & Level & As of & $\begin{array}{c}\text { 1-Year } \\
\text { Change * }\end{array}$ & $\begin{array}{c}\sim \text { Y Year } \\
\text { ago }\end{array}$ & $\begin{array}{c}\sim 10 \text { Year } \\
\text { ago }\end{array}$ \\
\hline Slovenia & 10.79 & 2007 & $-0.01 \%$ & 15.29 & 19.04 \\
Slovak Republic & 5.04 & 2006 & $-0.56 \%$ & 16.42 & 8.94 \\
Romania & 25.04 & 2007 & $-0.09 \%$ & 31.39 & 23.94 \\
Poland & 10.32 & 2006 & $-0.06 \%$ & 12.99 & 16.18 \\
Macedonia & 44.70 & 2007 & $0.05 \%$ & 37.07 & 34.89 \\
Czech Republic & 7.40 & 2006 & $0.00 \%$ & 9.45 & 12.30 \\
Croatia & 14.52 & 2007 & $-0.05 \%$ & 17.71 & 20.80 \\
Bulgaria & 26.79 & 2007 & $-0.04 \%$ & 32.35 & 22.85 \\
\hline
\end{tabular}

* percentual change relative to last year's value.

Among the more developed G20 economies, Figure 3 reveals that the highest levels for water pollution caused by the textile industry are found in Turkey (32.21\%), Indonesia (29.25\%) and China (20.29\%), while the lowest are in Germany (2.44\%), the U.K. (4.26\%) and the USA (4.29\%). Without exception, all of the $\mathrm{G} 20$ countries achieved decreasing rates for their $\mathrm{CO}_{2}$ emissions in the last reported decade.

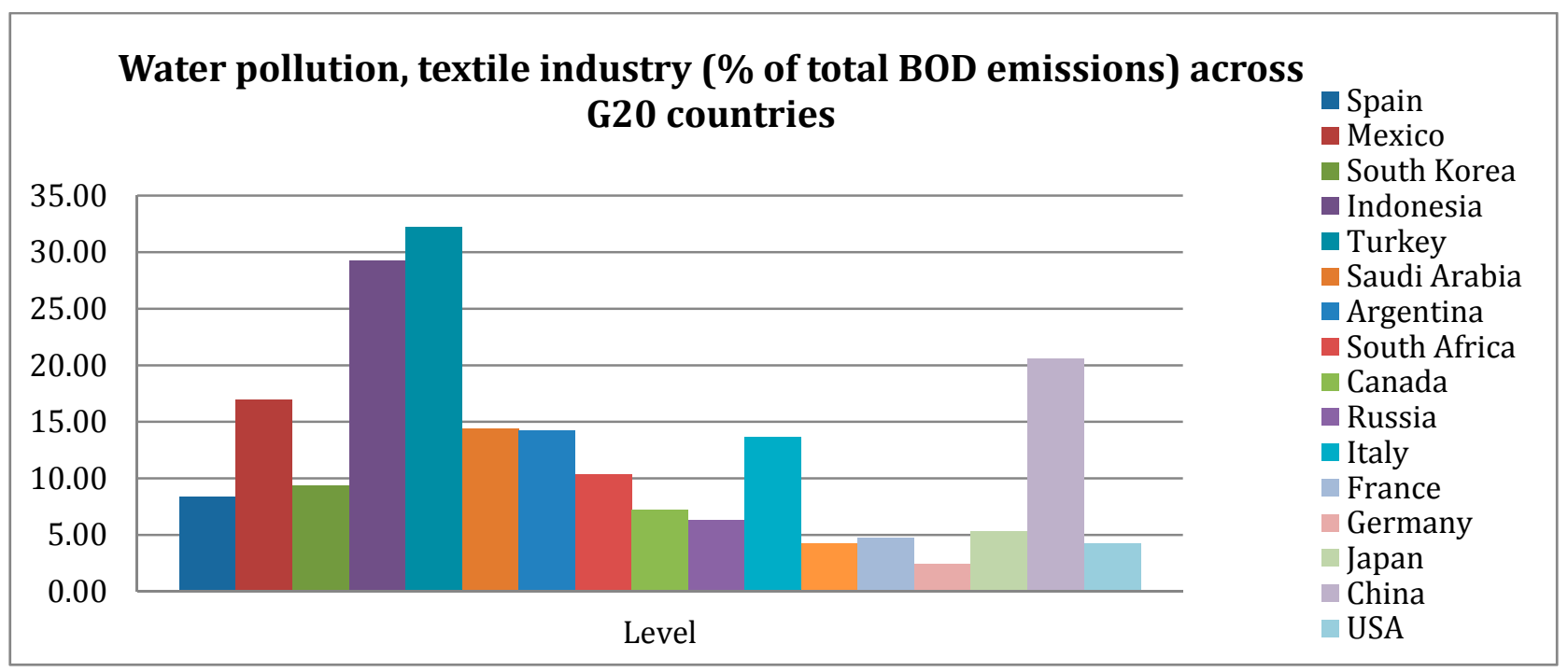

Figure 3. Water pollution caused by the textile industry, G20 countries.

\subsection{Methodology}

For both Romania and Poland, we make a forecast for the evolution of the two pollution indicators employed in this research, i.e., total emissions of organic water pollutants (measured in kilograms per day) and water pollution caused by the textile industry (as a percentage of BOD) over the next ten years. For this scope, we employ the Holt-Winters model [18-21]).

The Holt-Winters Model was first proposed in the early 1960s and uses a process known as exponential smoothing. It applies three exponential smoothing formulae to the series, respectively to the mean, trend and each seasonal sub-series, in the following manner:

$$
\begin{gathered}
\mathrm{a}_{t}=\alpha\left(Y_{t}-\mathrm{s}_{t-p}\right)+(1-\alpha)\left(\mathrm{a}_{t-1}+\mathrm{b}_{t-1}\right) \\
\mathrm{b}_{t}=\beta\left(\mathrm{a}_{t}-\mathrm{a}_{t-1}\right)+(1-\beta) \mathrm{b}_{t-1}
\end{gathered}
$$




$$
\mathrm{s}_{t}=\gamma\left(Y_{t}-\mathrm{a}_{t}\right)+(1-\gamma) \mathrm{s}_{t-p}
$$

where:

$\alpha, \beta$ and $\gamma$ are the smoothing parameters;

$\mathrm{a}_{t}$ is the smoothed level at time $t$;

$\mathrm{b}_{t}$ is the change in the trend at time $t$;

$\mathrm{S} t$ is the seasonal smoothing at time $t$;

$p$ is the number of seasons per year.

The Holt-Winters forecasts are then calculated using the latest estimates from the appropriate exponential smoothing that has been applied to the series.

Therefore, we have our forecast for the time period $T+\tau$ :

$$
\hat{y}_{T+\tau}=\mathrm{a}_{T}+\tau \mathrm{b}_{T}+\mathrm{s}_{T}
$$

where:

$\mathrm{a}_{T}$ is the smoothed estimate of the level at time $T$;

$\mathrm{b}_{T}$ is the smoothed estimate of the change in the trend value at time $T$;

$\mathbf{S}_{T}$ is the smoothed estimate of the appropriate seasonal component at $T$.

\section{Results and Discussion}

Figure $4 \mathrm{a}, \mathrm{b}$ shows that although total emissions of organic water pollutants decreased consistently during the 1990-2007 period in Romania (Figure 4b), the contribution of the textile industry to pollution has increased (Figure 4a). Indeed, water pollution caused by the textile industry in Romania had a constant decreasing trend until 1995, and from 1998, it started to increase sharply, with this upward trend continuing until the year 2004, after which, a reversal occurred, but the last data level is above the initial value.

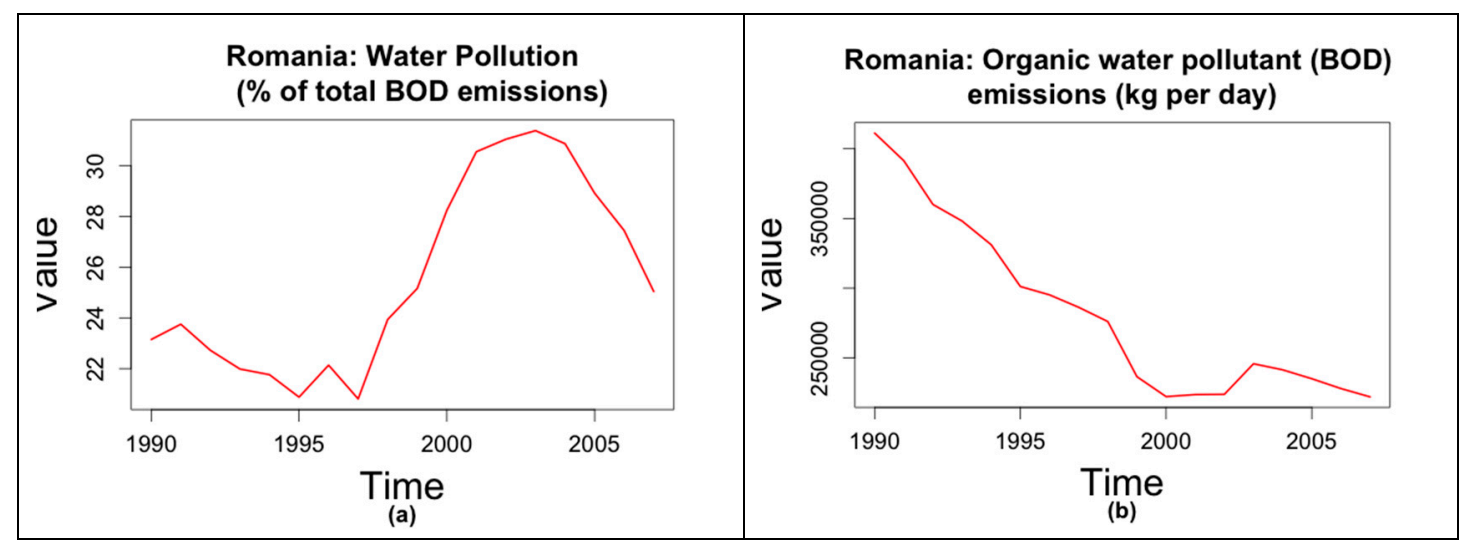

Figure 4. (a) Romania: water pollution caused by the textile industry; (b) Romania: total emissions of organic water pollutants.

A similar story is true in the case of Poland, with the main difference being that Poland managed to decrease both its total organic water pollutant emissions and the contribution of the textile industry to pollution during the analysis period (Figure 5a,b). Nevertheless, as seen in Section 2, it remains the most 
polluting country in the Eastern European area. Total emissions of organic water pollutants decreased sharply in Poland until 2002, after which, a reversal occurred (Figure 5b), while the contribution of the country's textile industry to water pollution continued the decreasing trend during the whole analysis period (Figure 5a).

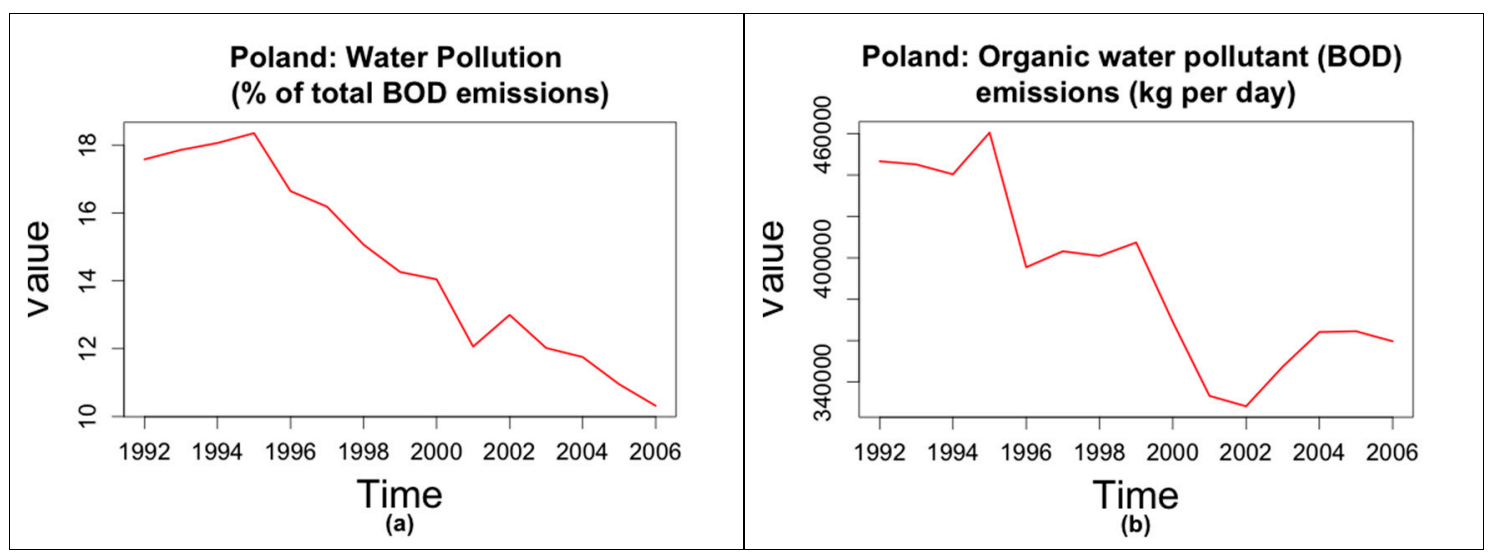

Figure 5. (a) Poland: water pollution caused by the textile industry; (b) Poland: total emissions of organic water pollutants.

The graphical representation of data in Figures 4 and 5 indicates that this time series appears to be non-seasonal and can be described using an additive model. Thus, for a clearer view of the trend, we will use a smoothing method, by calculating the simple moving average of the time series of order three.

The data smoothed with a simple moving average of order three confirms that organic water pollutant emissions decreased in both countries during the selected period, while the contribution of the textile industry to pollution followed a decreasing trend only in Poland, while Romania registered an increase over the 1998-2004 period.

To make forecasts for both total emissions of organic water pollutants (measured in kilograms per day) and water pollution caused by the textile industry (measured in percentages of total BOD emissions) in Romania and Poland for the following decade, we fit a predictive model using the HoltWinters() function in R, where we set the parameter gamma =FALSE, as our time series appears to be non-seasonal.

Table 2 presents the estimation results for both indictors and both countries.

Table 2. Estimated coefficients of Holt-Winters model.

\begin{tabular}{ccc|cc}
\hline \multirow{2}{*}{ Coefficients } & \multicolumn{2}{c|}{$\begin{array}{c}\text { Total Emissions of Organic Water } \\
\text { Pollutants (Kilograms per Day) }\end{array}$} & \multicolumn{2}{c}{$\begin{array}{c}\text { Water Pollution Caused by the Textile } \\
\text { Industry (\% of Total BOD Emissions) }\end{array}$} \\
\hline & POLAND & ROMANIA & POLAND & ROMANIA \\
\hline a & $359,893.8730$ & $222,102.500$ & 10.4199881 & 25.197353 \\
b & -588.7619 & $-4,951.716$ & -0.6754701 & -2.287893 \\
Forecasts SSE & $848,633.7659$ & $799,484.4617$ & 9.882093 & 27.83826 \\
\hline
\end{tabular}

Figure $6 \mathrm{a}-\mathrm{d}$ plots the original time series as a black line, with the forecasted values as a red line. We can observe that the in-sample forecasts agree pretty well with the observed values, although they tend to lag behind the observed values a little bit. 


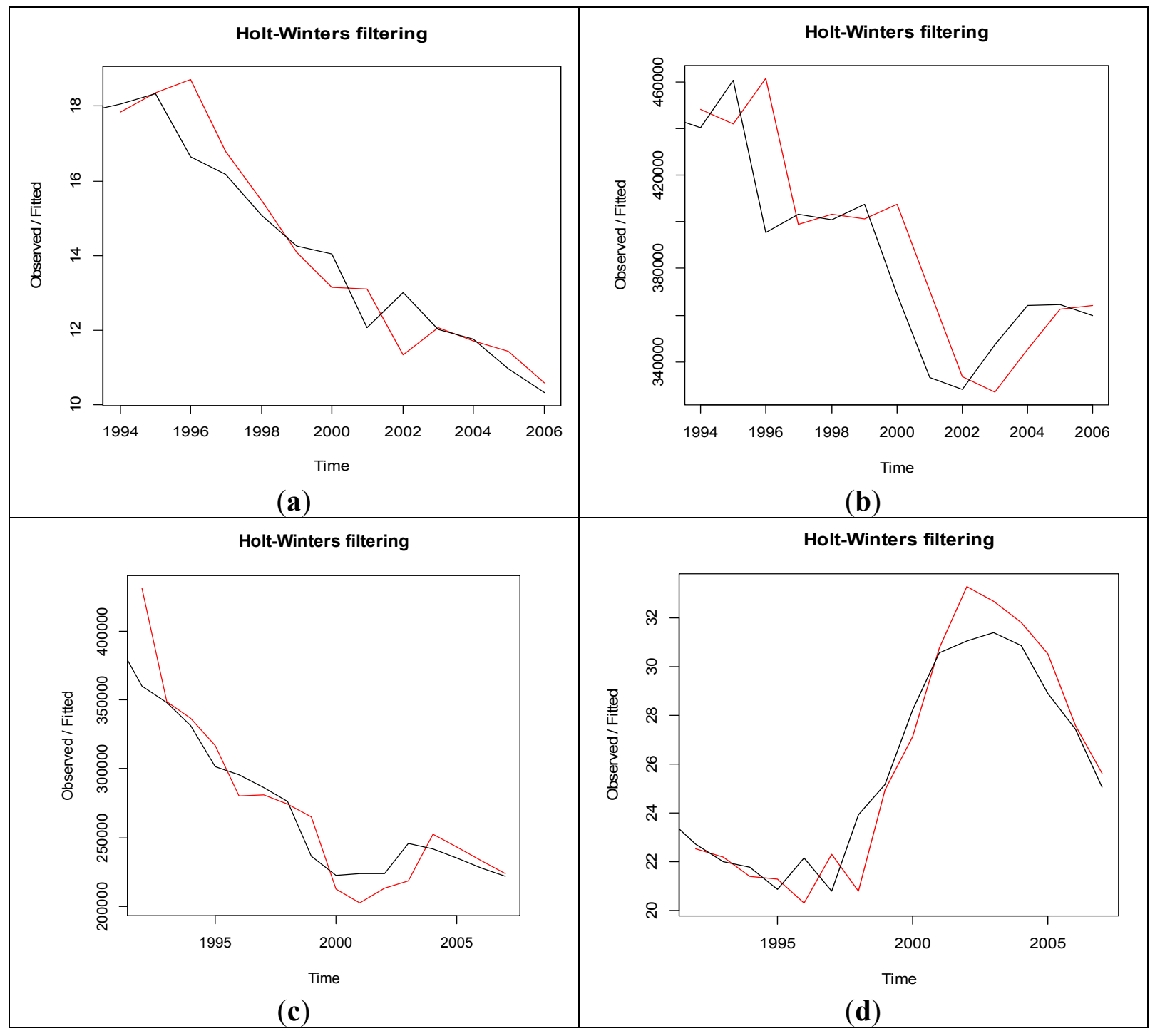

Figure 6. (a) Water pollution of the textile industry in Poland; (b) Poland: organic water pollutant (BOD) emissions (kg per day); (c) Romania: organic water pollutant (BOD) emissions (kg per day); (d) water pollution textile industry in Romania.

Next, we make forecasts for total organic water pollutant (BOD) emissions and for water pollution caused by the textile industry in Poland and Romania in from 2007-2017. Figure 7a-d reflects the predictions made by the Holt-Winters model as a blue line, with the $80 \%$ prediction interval as a dark shaded area and the $95 \%$ prediction interval as a lighter shaded area. The decreasing trend is obvious in all cases. According to our estimates, the contribution of the textile industry to water pollution will be $3.66 \%$ by the end of the year 2016 in Poland and 2.35\% by the end of 2017 in Romania. Both countries are headed towards complete elimination of pollution caused by the textile industry and, hence, towards a sustainable industrial sector, as Greenpeace intended with the release of its reports. 


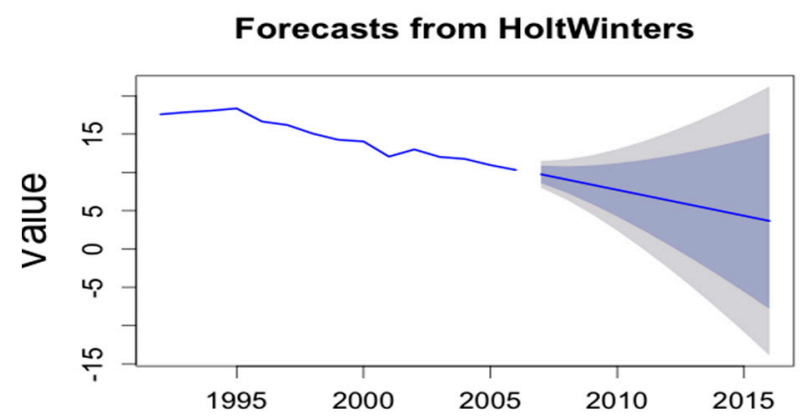

(a)

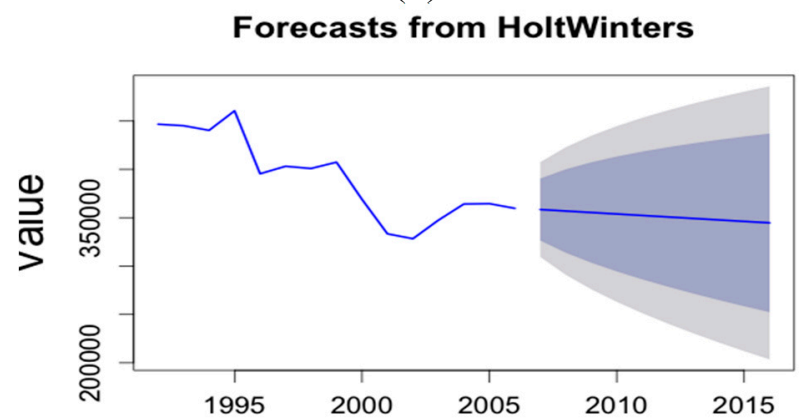

(b)

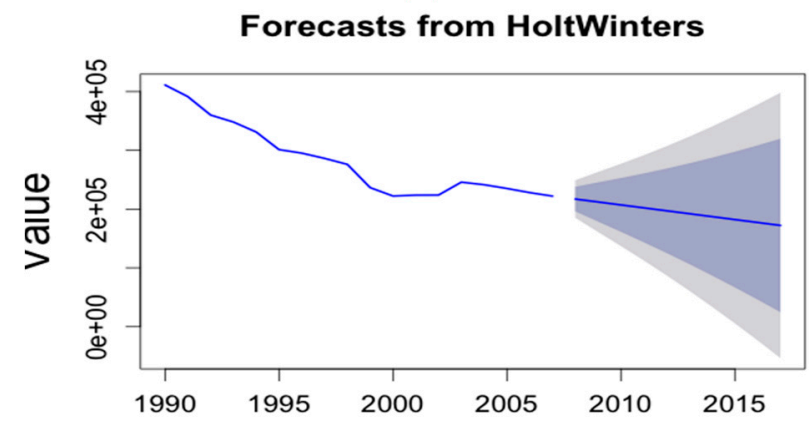

(c)

Forecasts from HoltWinters

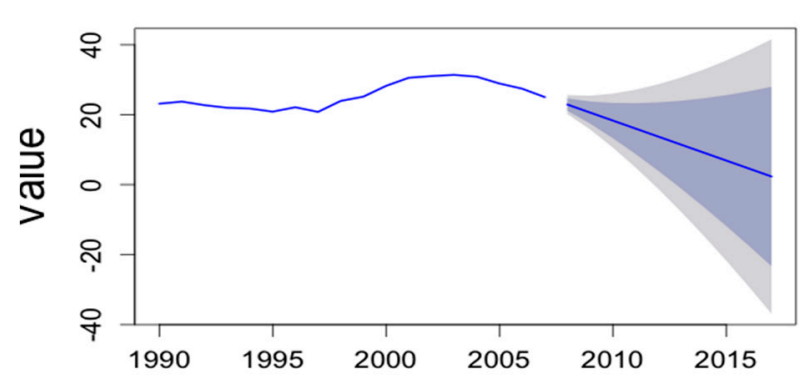

(d)

Figure 7. (a) Prediction of water pollution caused by the textile industry: Poland; (b) prediction of organic water pollutant (BOD) emissions (kg per day): Poland; (c) prediction of organic water pollutant (BOD) emissions (kg per day): Romania; (d) prediction of water pollution caused by the textile industry: Romania.

Finally, we check the accuracy of the forecast by calculating a correlogram of the in-sample forecast errors (Figure 8a-d). We notice from the sample correlograms that the autocorrelations at Lags 1-20 are all within the significance bounds, which proves that our forecast model is correctly 
specified, as there is no autocorrelation left in the residuals. Further, the Ljung-Box test is carried out in order to test whether there is significant evidence for non-zero correlations at Lags 1-20, and it also confirms the accuracy of the models in all cases (all calculated $p$-values are above 0.6 , so we conclude that no statistically significant correlations are left, which is required for a well-specified prediction model). The results therefore attest that both Poland and Romania are reducing their total organic water pollutant (BOD) emissions and the water pollution caused by the textile industry.

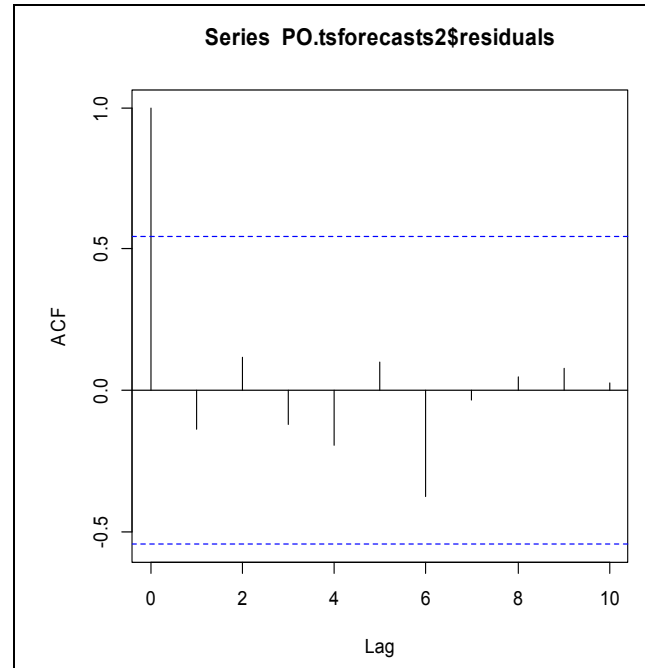

(a)

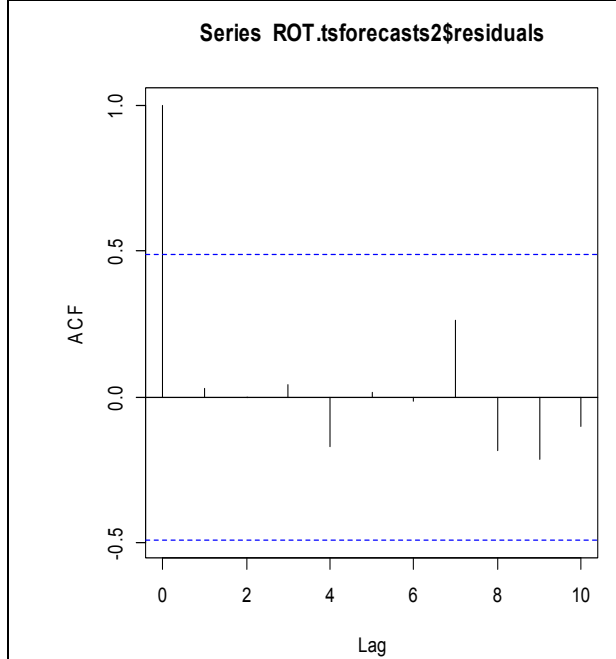

(c)

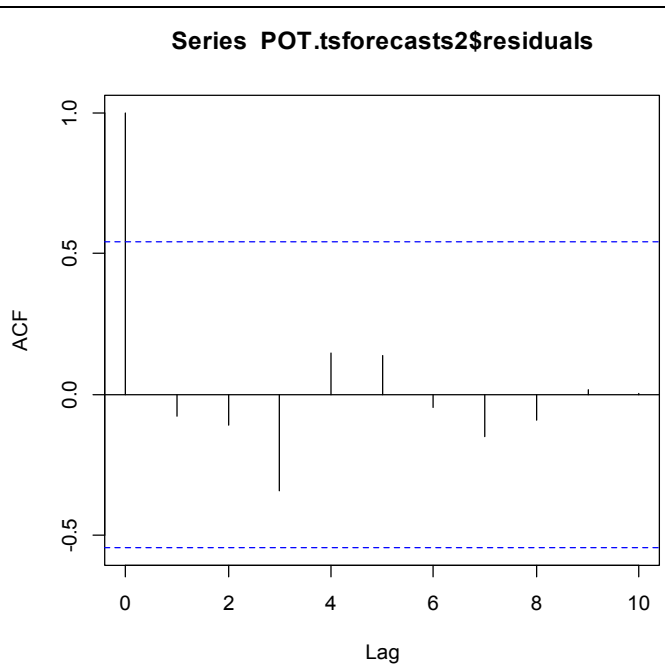

(b)

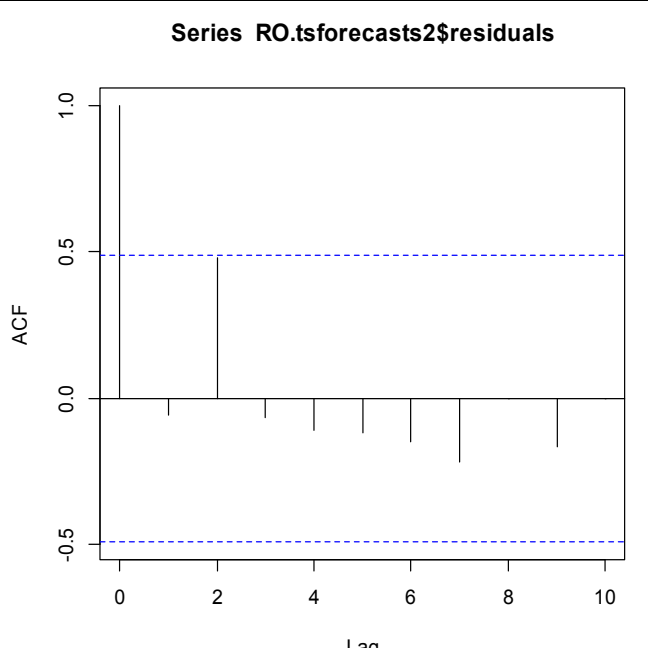

(d)

Figure 8. (a-d) Correlograms of the in-sample forecast errors for the four time series.

\section{Conclusions}

China, the USA and Russia are the biggest emitters of organic water pollutants (BOD) in the world, while Poland and Romania take the first two positions in Eastern Europe. The textile industry is one of the main contributors to water pollution, causing more than $20 \%$ of the registered levels of water pollution in countries like Turkey, Indonesia and China (among the G20 group of countries). In Eastern Europe, the percentage of total water pollution that is caused by the textile industry is lowest in the Slovak Republic, Czech Republic and Poland, while in Macedonia, the textile industry is guilty of contributing $44 \%$ to this phenomenon. The good news is that compared to the levels achieved in 1990 , 
most Eastern European countries managed to decrease water pollution caused by the textile industry. The only exceptions are Romania ( $+4.59 \%$ as compared to 1990$)$, Bulgaria $(+17.24 \%)$ and Macedonia $(+28.11 \%)$, which registered increases in this phenomenon.

Given the controversy created by the textile industry's contribution to pollution at a global level, this paper forecasts the trend of the total emissions of organic water pollutants, as well as of the textile industry's contribution to pollution over the next decade for the two Eastern European countries included in the analysis, i.e., the top polluters Poland and Romania. Predictions made with the Holt-Winters forecasting model reflect a continuous decrease of both pollution indicators in both countries, with a point estimate of the contribution of the textile industry to water pollution of $3.66 \%$ by the end of the year 2016 in Poland and of $2.35 \%$ by the end of 2017 in Romania. All models are correctly specified as attested by standard econometric tests, which allows us to confirm that both countries are headed towards almost complete elimination of pollution caused by the textile industry in the near future.

Corroborated by the fact that, in general, any action plan to foster sustainable development will need to include pollution reduction measures, we conclude that the Eastern European countries analyzed in this research are on their way towards a more sustainable industrial sector.

\section{Acknowledgments}

This research was supported by CNCS-UEFISCDI (National University Research Council- Executive Agency for Higher Education, Research, Development and Innovation), Project Number IDEI 303, Code PN-II-ID-PCE-2011-3-0593.

\section{Author Contributions}

The three authors contributed equally to Sections 1, 3 and 4, while Cristiana Tudor contributed to Section 2. Cristiana Tudor prepared the manuscript and all authors were involved in discussing the study. All authors have read and approved the manuscript.

\section{Conflicts of Interest}

The authors declare no conflict of interest.

\section{References}

1. Dirty Laundry: Unravelling the corporate connections to toxic water pollution in China. Available online: http://www.greenpeace.org/international/Global/international/publications/toxics/Water\% 202011/dirty-laundry-12pages.pdf (accessed on 5 September 2014).

2. Clothing to dye for: The textile sector must confront water risks. Available online: http://www.theguardian.com/sustainable-business/dyeing-textile-sector-water-risks-adidas (accessed on 5 September 2014)

3. Parvathi, C.; Maruthavanan, T.; Prakash, C. Environmental impacts of textile industries. Indian Text. J. 2009, CXVII, 22-26. 
4. Dirty Laundry 2: Hung Out to Dry. Unravelling the toxic trail from pipes to products. Available online: http://www.greenpeace.org/international/Global/international/publications/toxics/Water\% 202011/dirty-laundry-report-2.pdf (accessed on 5 September 2014).

5. Tudor, C. Modeling the Evolution of the Romanian Textile Industry: Empirical Evidence of Lead-lag and Causal Relationships. Fibres Text. East. Eur. 2012, 20, 8-12.

6. Domańska, D.; Wojtylak, M. Application of fuzzy time series models for forecasting pollution concentrations. Expert Syst. Appl. 2012, 39, 7673-7679.

7. Osowski, S.; Garanty, K. Forecasting of the daily meteorological pollution using wavelets and support vector machine. Eng. Appl. Artif. Intell. 2007, 20, 145-155.

8. Niska, H.; Hiltunen, T.; Karppinen, A.; Ruuskanen, J.; Kolehmainen, M. Evolving the neural network model for forecasting air pollution time series. Eng. Appl. Artif. Intell. 2004, 17, 159-167.

9. Ziomas, I.C.; Melas, D.; Zerefos, C.S.; Bais, A.F.; Paliatsos, A. Forecasting peak pollutant levels from meteorological variables. Atmos. Environ. 1995, 29, 3703-3711.

10. Sahu, S.; Mardia, K.V. A Bayesian kriged Kalman model for short-term forecasting of air pollution levels. J. R. Stat. Soc. Ser. C (Appl. Stat.) 2005, 54, 223-244.

11. Kurt, A.; Gulbagci, B.; Karaca, F.; Alagha, O. An online air pollution forecasting system using neural networks. Environ. Int. 2008, 34, 592-598.

12. Ibarra-Berastegi, G.; Elias, A.; Barona, A.; Saenz, J.; Ezcurra, A.; Argandoña, J. From diagnosis to prognosis for forecasting air pollution using neural networks: Air pollution monitoring in Bilbao. Environ. Model. Softw. 2008, 23, 622-637.

13. McCollister, G.M.; Wilson, K.R. Linear stochastic models for forecasting daily maxima and hourly concentrations of air pollutants. Atmos. Environ. 1975, 9, 417-423.

14. Zavadskas, E.K.; Kaklauskas, A.; Kaklauskiene, J. Modelling and forecasting of a rational and sustainable development of Vilnius: Emphasis on pollution. Environ. Pollut. 2007, 30, 485-500.

15. Singh, K.P.; Basant, A.; Malik, A.; Jain, G. Artificial neural network modeling of the river water quality-A case study. Ecol. Model. 2009, 220, 888-895.

16. Rauch, W.; Harremoës, P. The importance of the treatment plant performance during rain to acute water pollution. Water Sci. Technol. 1996, 34, 1-8.

17. Zhu, Z.; Deng, Q.; Zhou, H.; Ouyang, T.; Kuang, Y.; Huang, N.; Qiao, Y. Water pollution and degradation in Pearl river Delta, South China. AMBIO A J. Hum. Environ. 2002, 31, 226-230.

18. Chatfield, C. The Holt-Winters Forecasting Procedure. Appl. Stat. 1978, 27, 264-279.

19. Gelper, S.; Fried, R.; Croux, C. Robust forecasting with exponential and Holt-Winters smoothing. J. Forecast. 2010, 29, 285-300.

20. Holt, C.C. Forecasting Trends and Seasonals by Exponentially Weighted Averages. Int. J. Forecast. 2004, 20, 5-10.

21. Lynwood, A.; Johnson, D.; Montgomery, C.; Gardiner, J.C. Forecasting and Time Series Analysis, 2nd ed.; McGraw-Hill Inc: New York, NY, USA, 1990.

(C) 2015 by the authors; licensee MDPI, Basel, Switzerland. This article is an open access article distributed under the terms and conditions of the Creative Commons Attribution license (http://creativecommons.org/licenses/by/4.0/). 